\title{
Determinants of chronic bronchitis and lung dysfunction in Western Australian gold miners
}

\author{
C D J HOLMAN, P PSAILA-SAVONA, M ROBERTS, J C McNULTY \\ From the Public Health and Scientific Support Services, Health Department of Western Australia, Perth 6000, \\ Western Australia
}

\begin{abstract}
The relation of chronic bronchitis and respiratory dysfunction to age, tobacco smoking, and occupational exposure to surface and underground mining operations were examined in a cross 3 sectional survey of 1363 men employed in the Kalgoorlie mining industry in 1985. Overall, the $\$$ prevalence of chronic bronchitis was $14 \%$. Eleven per cent of the workers had obstructive lung $\vec{N}$ disorder $\left(\mathrm{FEV}_{1} / \mathrm{FVC}<0.70\right)$ and $9 \%$ had restrictive lung disorder $(\mathrm{FVC}<0.80$ of predicted for $\stackrel{\infty}{\circ}$ height and age). There was little change in the prevalence of chronic bronchitis from that observed $\overrightarrow{0}$ in a survey of the same industry in 1961-2. Only $1 \%$ of the workers in 1985 had radiographic signs $\frac{\text { o }}{2}$ of silicosis compared with $22 \%$ in 1961-2. Age, smoking, and underground mining experience all $\vec{\nabla}$ exerted strong effects on the development of chronic bronchitis with or without associated respira- $\mathbb{D}$ tory function abnormalities. After control of confounding by age and smoking, it was estimated $\Phi$ that compared with a lifetime non-miner, the odds ratio (OR) of chronic bronchitis was $1.8(95 \%$ 응 confidence interval, $1 \cdot 0-3 \cdot 3)$ for one to nine years underground mining gold, $2 \cdot 5(1 \cdot 2-5 \cdot 2)$ for $10-19 \stackrel{\mathbb{D}}{-}$ years, and $5 \cdot 1(2 \cdot 4-10 \cdot 9)$ for 20 or more years. Underground mining of minerals other than gold w⿰8乛 $\vec{\oplus}^{\infty}$ also associated with chronic bronchitis $(\mathrm{OR}=5 \cdot 1 ; 95 \% \mathrm{CI}, 1 \cdot 1-25 \cdot 0)$ whereas exclusive surfate.$v$ mining had only a small empirical effect $(\mathrm{OR}=1 \cdot 3 ; 95 \% \mathrm{CI}, 0.6-2 \cdot 5)$. It is estimated that the proportion of cases of chronic bronchitis in working underground miners due to occupationa factors is $50 \%$. The results support the existence of an industrial cause of chronic bronchitis, although caution must be exercised in generalising the results to miners with progressive and severe respiratory impairment.
\end{abstract}

For more than two decades the existence of industrial bronchitis and its importance as a cause of disability relative to smoking induced chronic obstructive pulmonary disease (COPD) have been debated. ${ }^{1-3}$ As early as 1832 , it was recognised that certain occupational groups had a higher than expected prevalence of bronchitic symptoms and an increased mortality from COPD relative to other members of the workforce. ${ }^{4}$ Groups at risk include coalminers, goldminers, asbestos miners, and millers, coke, steel, and cement workers, and textile manufacturers. ${ }^{1-5}$ The extent, however, to which a high prevalence of cigarette smoking and, possibly, other causative factors confound these apparent associations has been questioned. ${ }^{6}$ For example, the prevalence of bronchitis

Accepted 1 December 1986 and mortality from COPD are increased in miners' wives compared with wives of non-miners. ${ }^{78}$

There is a poor correlation between the development of radiological signs of pneomoconiosis and $?$ the presence of bronchitic symptoms, suggesting that the two conditions have different aetiologies. ${ }^{19-11}$ In the early 1960s the Minister for Pensions and National Insurance in Great Britain noted that coalminers with a clear chest $x$ ray film, but none the $\frac{\text { 의 }}{5}$ less disabled by severe obstructive bronchitis, were $\supset$ not eligible for insurance benefits. The Minister appointed a special committee of the Medical $\tilde{N}$ Research Council to investigate the matter and in 1966 the MRC reported that exposure to dust did not $\tilde{O}$ appear to be an important factor in determining the prevalence of bronchitis in British coal miners. ${ }^{7}$ Furthermore, the MRC concluded that even if there were incontrovertible evidence that chronic bronchitis was more prevalent among workers in certain occupations $\stackrel{\mathcal{Q}}{+}$ 
than in others, it would not be possible on the basis of any known form of clinical examination to measure the extent to which the disease in any individual was due to his occupation. ${ }^{7}$ The conclusions of the MRC, and especially their pessimistic outlook for the future, provoked a storm of controversy which, at a reduced level, still continues today.

Despite obvious limitations, some progress in substantiating and understanding industrial bronchitis has been achieved. In a study of 8555 miners in the Appalachian coal fields the prevalence of bronchitis was found to be higher in smoking miners than in non-smokers and ex-smokers working in similar dust conditions. ${ }^{12}$ Only among non-smokers, however, had those with high dust exposure (face workers) more bronchitis than those with lower dust exposure (surface workers). An additional effect of exposure to dust was not seen in smokers or ex-smokers. ${ }^{12}$ In South African gold miners associations of chronic bronchitis and airways obstruction with exposure to dust containing $75 \%$ free silica have been observed separately in smokers, ex-smokers, and nonsmokers. ${ }^{13}$ Similarly, in a survey performed a decade earlier in the Transvaal, a higher prevalence of chronic bronchitis was observed in smoking gold miners compared with smoking non-miners, although there was no difference between non-smoking miners and non-smoking controls. ${ }^{14}$

The first and only previous health survey of gold miners in Kalgoorlie, Western Australia, was performed in 1961-2. ${ }^{15}$ The prevalence of chronic bronchitis was $10 \%$ in surface workers and $27 \%$ in underground workers and increased with number of years of mining. The investigator noted that $73 \%$ of underground miners were current smokers compared with $64 \%$ of surface workers, and concluded that likely confounding by smoking made interpretation of the results difficult. ${ }^{15}$

The present investigation was performed, firstly, because it was considered timely and necessary to review the respiratory health of Kalgoorlie gold miners and, secondly, with improved analytical methods to examine the relation of chronic bronchitis and respiratory function abnormalities to occupational factors in the gold mining industry.

\section{Methods}

The Western Australian mining town of Kalgoorlie is $550 \mathrm{~km}$ east of the capital city of Perth, in a hot, dry environment on the edge of the Nullarbor Plain. The "Golden Mile" at Kalgoorlie is the source of some $40 \%$ of Australia's total gold production. In 1984 the total mining workforce was about 1700 people, of whom 1144 held mining certificates. Around 800 were employed in underground work.

\section{STUDY SUBJECTS}

The survey took place from 29 October to 15 November 1985 and was held in conjunction with the compulsory chest $x$ ray examinations required for miners to renew their mining certificates. Regulations made under the Mines Regulation Act prescribe that workers employed in underground mines and most surface mining operations shall undergo medical examinations at periodic intervals. For the purpose of the 1985 survey, the Mines Medical Officer ruled that the medical examination would consist of a chest $x$ ray examination, respiratory function test, and respiratory symptom questionnaire.

All workers at the three major mining companies and at a nickel smelter were asked to participate in the survey, regardless of whether or not they had a mining certificate. The nickel smelter was included, firstly, because many of the employees had been certified miners and, secondly, because employees at the smelter who had no mining experience were considered to constitute a valid reference group against which the effects of working underground could be assessed. A total of 1393 subjects were surveyed, 30 of whom were female surface workers. The proportions of current employees surveyed were estimated as $99 \%, 94 \%$, and $80 \%$ in each of the three mining companies and $97 \%$ at the smelter.

\section{SURVEY INSTRUMENTS}

Survey measurements were undertaken at the working sites by use of a mobile chest $x$ ray unit and three caravan rigs housing other equipment.

Chest $x$ ray films-These were posteroanterior films taken in the standing position with a fully inspired chest. Films were subsequently read for the presence of silicosis by an experienced chest physician. Positive and doubtful films were reviewed by an occupational health physician and in cases of disagreement a second occupational health physician was asked to adjudicate. All three observers were unaware of the others' determinations.

Respiratory symptom questionnaire-The 1976 MRC respiratory symptom questionnaire was administered to all subjects in accordance with the "Instructions to interviewers."16 In addition to the standard questions, a supplementary section on employment history was included. This recorded the subject's present occupation and the number of years worked in total as a miner in the industries of gold, coal, iron ore, asbestos, and other mining. In each industry separate recordings were made for surface and underground work. Durations of employment were rounded to the nearest year except that short employment of more than one month (five months mining gold underground, for example) was rounded up to one year so as to preserve the integrity of the 
unexposed group.

Lung function test-Tests of forced vital capacity (FVC) and the forced expiratory volume in the first second of exhalation $\left(\mathrm{FEV}_{1}\right)$ were administered according to the guidelines of the American Thoracic Society..$^{17}$ The equipment used, three single wedge bellows Vitalograph spirometers, was precalibrated by an air syringe to ensure standardisation of readings. Lung function tests were performed in the standing position with no nose clip, after removal of false teeth. At least three tracings per subject were obtained with the requirement that the volume of the best two did not vary by more than approximately $5 \%$ or $100 \mathrm{ml}^{1{ }^{17}} \mathrm{FEV}_{1}$ and FVC were taken as the largest of the observed readings and converted to BTPS (body temperature, pressure, and water saturation). Predicted FVC based on age and height measured during the survey were derived from the prediction formulae of the National Health and Medical Research Council of Australia. ${ }^{18}$

\section{ANALYTICAL METHODS}

The survey data were processed using the Statistical Package for the Social Sciences. ${ }^{19}$ To provide a single measure of tobacco consumption, levels of rolled tobacco and pipe tobacco were converted to cigarette equivalents on the basis that one cigarette equals one gram of tobacco. Confidence intervals associated with estimates of the proportions of subjects having chronic bronchitis and other conditions were calculated by the method of Wilson. ${ }^{20}$ Confidence intervals around prevalence ratio estimates were obtained using a natural logarithm transformation. ${ }^{21}$

Logistic regression analysis of the simultaneous effects of two or more factors was performed by the RISK computing package. ${ }^{22}$ The effect measure derived from the unconditional logistic regression of cross sectional survey data is the prevalence odds ratio (POR), which takes the form,

$$
\text { POR }=\frac{P_{1}}{\left(1-P_{1}\right)} / \frac{P_{0}}{\left(1-P_{0}\right)}
$$

where $P_{1}$ is the prevalence of disease in the exposed and $P_{0}$ is the prevalence in the unexposed. For a rare disease the POR approximates to the prevalence ratio, $\mathbf{P}_{1} / \mathbf{P}_{0}$. Because chronic bronchitis and abnormalities of lung function were not rare in Kalgoorlie mining workers, however, the PORs were more extreme in value than the corresponding prevalence ratios. Despite the lack of approximation of the PORs to prevalence ratios in this study, the POR has another useful interpretation. If the average duration of disease is similar in exposed and unexposed cases, and the disease does not affect exposure status, then the POR approximates to the incidence rate ratio. ${ }^{23}$ Thus the POR of chronic bronchitis in miners compared with non-miners approximates to the ratio of the incidence rate of chronic bronchitis in miners rela- $\overline{\bar{\alpha}}$ tive to non-miners, provided that the average $\frac{2}{3}$

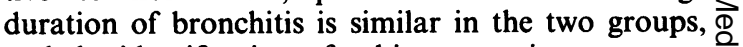
and the identification of subjects as miners or non- $\stackrel{?}{\Rightarrow}$ miners remains unchanged. As most of the recorded exposures were of a historical nature, the latter assumption was reasonably applied.

The logistic regression models included binary indi- $\frac{\bar{\sigma}}{\bar{\omega}}$. cators for age, duration of smoking, level of tobacco $\frac{\vec{\Phi}}{\Phi}$ consumption, current smoking status, and mining experience. Age was represented by five binary indicators for age groups $10-19,30-39,40-49,50-59, \vec{\circ}$ and $\geqslant 60$ years, with ages $20-29$ years as the reference $\overrightarrow{\vec{c}}$ category. The preferred combination of smoking vari- $\vec{\omega}$ ables was to assign three binary indicators for $\frac{}{\circ}$ different durations of smoking history $\left(1-9,10-19, \frac{\mathbb{D}}{3}\right.$ and $\geqslant 20$ years) and to set further indicators in those smokers who consumed $20-39$ or 40 or more cigarette equivalents a day, and who were current smokers. $\vec{N}$ The different types of mining experience were com- $\vec{a}$ pressed into a single exposure scale with the following mutually exclusive categories: never worked in mining $\mathrm{S}$ (reference category); surface mining only; gold min- $-\vec{\square}$ ing underground for $1-9,10-19$, and 20 or more $\underset{\mathbb{D}}{\square}$ years; and underground mining of minerals other $\mathbb{\complement}$ than gold. The mining exposure scale was represented $\frac{\partial}{\sigma}$ by five binary indicators. To adjust for confounding between age, smoking, and mining experience all $\vec{\bullet}$ binary indicators were included simultaneously in the logistic regression model.

Indices of multiplicative and additive synergy, and $S_{A}$ were calculated by the method of Rothman. Empirically, $\mathrm{S}$ greater than unity is indicative of syn- $\overline{0}$ ergy between factors, whereas $S$ less than 1 indicates antagonism.

\section{Results}

The analysis of results was restricted to the 1363 male employees. Table 1 summarises their characteristics $\bar{\partial}$ with respect to age, smoking habits, and mining $\frac{\mathbb{D}}{3}$ experience. Most $(81 \%)$ were aged $20-49$ and a high proportion $(75 \%)$ were current smokers or ex- 3 . smokers. Among the male workers $42 \%$ had smoked $\rho$ the equivalent of 20 cigarettes or more a day and $52 \%$ had smoked for ten or more years.

Just over half $(51 \%)$ of the men were underground workers and almost one quarter $(24 \%)$ were treatment plant operators, mainly at the smelter. The remaining quarter were engaged in various types of $\mathrm{N}$ surface work associated with mining operations (table $\mathrm{N}$ 1). Because several of the smelter workers were ex- స్ miners, only $17 \%$ of the men had never worked on a $\sigma$ mining site. Sixty per cent had worked underground in a gold mine for more than one month and $31 \%$ had been employed to mine gold underground for five or 
Table 1 Distributions of 1363 male employees of the Kalgoorlie mineral industry according to age, smoking habits, and mining experience in 1985

\begin{tabular}{|c|c|c|}
\hline Characteristic & No & $\%$ \\
\hline \multicolumn{3}{|l|}{ Age: } \\
\hline $10-19$ & 67 & 4.9 \\
\hline $20-29$ & 466 & $34 \cdot 2$ \\
\hline $30-39$ & 400 & $29 \cdot 3$ \\
\hline $40-49$ & 237 & $17 \cdot 4$ \\
\hline $50-59$ & 159 & $11 \cdot 7$ \\
\hline$\geqslant 60$ & 34 & $2 \cdot 5$ \\
\hline \multicolumn{3}{|l|}{ Duration of smoking history (years): } \\
\hline Non-smoker & 345 & $25 \cdot 3$ \\
\hline $0-9$ & 306 & $22 \cdot 5$ \\
\hline $10-19$ & 331 & $24 \cdot 3$ \\
\hline$\geqslant 20$ & 381 & $28 \cdot 0$ \\
\hline \multicolumn{3}{|c|}{ Level of tobacco consumption (cigarette equivalents/day): } \\
\hline Non-smoker & 345 & $25 \cdot 3$ \\
\hline $1-19$ & 449 & 32.9 \\
\hline $20-39$ & 492 & $36 \cdot 1$ \\
\hline$\geqslant 40$ & 77 & 5.6 \\
\hline \multicolumn{3}{|l|}{ Present smoking status: } \\
\hline Non-smoker & 345 & $25 \cdot 3$ \\
\hline Ex-smoker & 252 & $18 \cdot 5$ \\
\hline Current smoker & 766 & $56 \cdot 2$ \\
\hline \multicolumn{3}{|l|}{ Present occupational category: } \\
\hline Underground worker & 696 & $51 \cdot 1$ \\
\hline Treatment plant operator & 324 & 23.8 \\
\hline Other surface worker & 343 & $25 \cdot 2$ \\
\hline Ever worked on a mining site & 1126 & $82 . \overline{4}$ \\
\hline Ever worked underground in a mine & 860 & $63 \cdot 1$ \\
\hline $\begin{array}{l}\text { Ever engaged in surface work at a } \\
\text { gold mine }\end{array}$ & 616 & $45 \cdot 2$ \\
\hline \multicolumn{3}{|c|}{ Underground gold mining experience (years): } \\
\hline Never & 543 & $\begin{array}{l}39 \cdot 8 \\
41.7\end{array}$ \\
\hline $\begin{array}{r}1-9 \\
10-19\end{array}$ & 569 & $41 \cdot 7$ \\
\hline $\begin{array}{l}10-19 \\
\geqslant 20\end{array}$ & $\begin{array}{l}147 \\
104\end{array}$ & $\begin{array}{r}10 \cdot 8 \\
7 \cdot 6\end{array}$ \\
\hline
\end{tabular}

more years. Forty five per cent of men had been engaged at some time in surface work at a gold mine. Only small proportions had ever worked in coal mines $(5 \%)$, asbestos mines $(2 \%)$, or mining iron ore $(4 \%)$. A substantial proportion (36\%), however, had mined a range of other minerals, particularly nickel.

\section{CHEST ILLNESS AND LUNG DYSFUNCTION}

Table 2 gives the prevalence estimates of chronic bronchitis and lung function abnormalities. The presence of chronic bronchitis, defined in the MRC questionnaire as the occurrence of a productive coughthat is, cough and phlegm - on most days for as much as three months each year was observed in $14 \%$ of those surveyed. Over the previous three years, $3 \%$ had periods of exacerbation of productive cough lasting three weeks or more. On direct questioning, a history of "bronchitis" was admitted by $17 \%$ of subjects.

Normal $\mathrm{FEV}_{1} / \mathrm{FVC}$ and $\mathrm{FVC}_{\mathrm{o}} / \mathrm{FVC}_{\mathrm{p}}$ ratios were observed in $89 \%$ and $91 \%$ of the male workers respectively. Normal results were defined as an FEV $_{1}$ of at least $70 \%$ of observed FVC and a ratio of observed to predicted FVC of $80 \%$ or greater. The grading of obstructive and restrictive lung disorders given in table 2 follows closely that recommended by Shigeoka. ${ }^{25}$ Three per cent of subjects had a moderate to severe obstructive disorder and almost $2 \%$ had a moderate or severe restrictive lung disorder.

The prevalence of chronic bronchitis was $29 \%$ in subjects with an obstructive lung disorder and $31 \%$ in those with a restrictive lung disorder. Only 37 subjects (3\%) had an indeterminant-that is, combined obstructive and restrictive-lung disorder according to spirometric testing. The prevalence of chronic bronchitis in that group was high, being $51 \%$. Some 1122 subjects $(82 \%)$ had no lung function abnormality but $11 \%$ of these still had symptoms of chronic bronchitis. Disease processes usually associated with a restrictive lung disorder include pulmonary fibrosis, pleural scarring, rib cage abnormalities, and pathological muscle weakness; whereas an obstructive lung disorder is more often associated with obstructive conditions such as COPD and bronchiectasis. ${ }^{25}$ On this basis it might be expected that chronic bronchitis would be more prevalent in people with an obstructive as opposed to a restrictive functional disorder. In fact, the results indicated that chronic bronchitis was associated with both types of lung function abnormality to a similar extent. The prevalence ratio of chronic bronchitis comparing subjects with and without an obstructive disorder was $2.45(95 \% \mathrm{CI}$, 1.84-3.28). For those with and without a restrictive lung disorder the prevalence ratio was 2.51 (1.86-3.41).

Only 16 male employees ( $1 \%$ ) had chest $x$ ray films assessed by the review panel as showing radiographic evidence of silicosis. Of these 16 , five $(31 \%)$ had chronic bronchitis, five (31\%) an obstructive lung disorder, and nine $(56 \%)$ a restrictive lung disorder. There was only one radiographically identified case of emphysema but 11 had evidence of fibrotic change.

Table 2 Prevalence of chronic bronchitis and lung function abnormalities in 1363 male employees of the Kalgoorlie mineral industry in 1985

\begin{tabular}{|c|c|c|}
\hline \multirow[b]{2}{*}{ Condition } & \multicolumn{2}{|c|}{ Prevalence } \\
\hline & Estimate & $95 \% C I$ \\
\hline Chronic bronchitis & 0.139 & $0.121-0.158$ \\
\hline $\begin{array}{l}\text { Chronic bronchitis, with period of } \\
\text { exacerbation in past } 3 \text { years }\end{array}$ & 0.032 & $0.024-0.042$ \\
\hline $\begin{array}{l}\text { History of "bronchitis" } \\
\text { Obstructive lung disorder: }\end{array}$ & $0 \cdot 171$ & $0.152-0.192$ \\
\hline $\begin{array}{l}\text { Mild to severe } \\
(\text { FEV } / \text { FVC }<70 \%) \\
\text { Moderate to severe }\end{array}$ & $0 \cdot 113$ & $0.097-0.131$ \\
\hline $\begin{array}{l}\left(\text { FEV }_{1} / \text { FVC }^{\prime}<60 \%\right) \\
\text { Severe }\left(\text { FEV }_{1} / \text { FVC }<45 \%\right)\end{array}$ & $\begin{array}{l}0.031 \\
0.004\end{array}$ & $\begin{array}{l}0.023-0.041 \\
0.002-0.009\end{array}$ \\
\hline $\begin{array}{l}\text { Restrictive lung disorder: } \\
\text { Mild to severe }\end{array}$ & & \\
\hline $\begin{array}{l}\text { (FVC }<80 \% \text { of predicted) } \\
\text { Moderate to severe }\end{array}$ & 0.091 & $0 \cdot 077-0 \cdot 107$ \\
\hline $\begin{array}{l}\text { (FVC }<65 \% \text { of predicted) } \\
\text { Severe (FVC }<50 \% \text { of predicted) }\end{array}$ & $\begin{array}{l}0.016 \\
0.006\end{array}$ & $\begin{array}{l}0.011-0.024 \\
0.003-0.012\end{array}$ \\
\hline
\end{tabular}


EFFECTS OF AGE

Table 3 shows the relations of chronic bronchitis and lung dysfunction to age. Different results are reported using the outcomes of chronic bronchitis, chronic bronchitis with obstructive lung disorder $\left(\mathrm{FEV}_{1} / \mathrm{FVC}\right.$ $<70 \%$ ), and chronic bronchitis with restrictive lung disorder (FVC $<80 \%$ of predicted). Both combinations of lung dysfunction and chronic bronchitis were studied because obstructive and restrictive lung disorders had the same propensity for association with chronic bronchitis in the survey population.

The rates of all three respiratory conditions were age related before and after adjustment for smoking habits and mining experience, although clearly the latter factors confounded the unadjusted age effects to a considerable degree. Age was a particularly strong determinant of chronic bronchitis when complicated by either type of lung function abnormality. It was estimated that at age 60 or more the rates of chronic bronchitis combined with obstructive or restrictive lung disorders were around 12-fold to 14-fold higher than in people aged 20-29 (table 3).

\section{EFFECTS OF SMOKING HABITS}

For the smoking results (table 4) the effect of any combination of duration of smoking, level of tobacco consumption, and current smoking status may be estimated by multiplying the corresponding PORs. For example, a current smoker of 30 cigarettes a day with a 15 year smoking history, on the basis of the results adjusted for age and mining experience in table 4 , is estimated to have a POR of $5.3(1.7 \times 1.3 \times 2.4)$ relative to a lifetime non-smoker.

It may be seen that with the exception of current smoking status, the adjusted effects in table 4 are much reduced compared with the unadjusted effects. Further examination of the data indicated that cur- rent smoking was negatively confounded with age, whereas the other two smoking measures were positively confounded with age and mining experience. Current smoking status was the strongest independent tobacco factor for chronic bronchitis with or without obstruction. Current smokers were estimated to have more than four times the rate of chronic bronchitis with obstruction observed in ex-smokers with a similar duration of smoking history and similar reported levels of tobacco consumption. This implies that the effects of tobacco smoke in causing bronchitis and respiratory obstruction were partially reversible. Current smoking had a lesser influence on chronic bronchitis complicated by restrictive lung disorder, possibly because the underlying pathology was less amenable to recovery.

\section{EFFECTS OF MINING EXPERIENCE}

Table 5 shows the relation of chronic bronchitis and associated lung dysfunction with occupational $\infty$ exposures to underground or surface mining. Each $\overrightarrow{0}$ POR corresponding to a mining category in table 5 윽 measures the effect of that exposure relative to people employed in the mineral industry who were never directly concerned with mining operations.

Experience in underground mining affected the rates of all three types of respiratory condition. Compared with a lifetime non-miner, after adjustment for confounding by age and smoking habits, it was est $\dot{B}$ mated that a person with 20 or more years of expere ence in underground gold mining had around five times the rate of chronic bronchitis, with or without functional obstruction, and eight times the rate of chronic bronchitis with a restrictive disorder. Underground experience in mining minerals other than gold conferred similar levels of risk, although the confidence intervals were wide due to the few subjects

Table 3 Relations of chronic bronchitis and lung dysfunction to age in 1363 male employees of the Kalgoorlie mineral industry, before and after adjustment for smoking habits and mining experience

\begin{tabular}{|c|c|c|c|c|c|c|}
\hline \multirow[b]{2}{*}{ Age (years) } & \multicolumn{2}{|c|}{ Chronic bronchitis } & \multicolumn{2}{|c|}{$\begin{array}{l}\text { Chronic bronchitis with FEV } V_{1} / F V C \\
<70 \%\end{array}$} & \multicolumn{2}{|c|}{$\begin{array}{l}\text { Chronic bronchitis with } \\
F V C<80 \% \text { of predicted }\end{array}$} \\
\hline & POR & $95 \% C I$ & $P O R$ & $95 \% C I$ & $P O R$ & $95 \% C I$ \\
\hline $\begin{array}{l}10-19 \\
20-29 \\
30-39 \\
40-49 \\
50-59 \\
\geqslant 60\end{array}$ & $\begin{array}{l}0 \cdot 3 \\
1 \cdot 0 \\
1 \cdot 6 \\
2 \cdot 3 \\
3 \cdot 8 \\
5 \cdot 1\end{array}$ & $\begin{array}{l}0.1-1.4 \\
1.0-2.5 \\
1.4-3.6 \\
2.4-6.2 \\
2.3-11.2\end{array}$ & $\begin{array}{c}\text { Before adjustme } \\
1.0 \\
0.9 \\
6.7 \\
13.8 \\
35.5\end{array}$ & $\begin{array}{rr}0 \cdot 2- & 3 \cdot 9 \\
2 \cdot 2-20 \cdot 8 \\
4 \cdot 6-41 \cdot 8 \\
10 \cdot 0-125 \cdot 7\end{array}$ & $\begin{array}{r}- \\
1 \cdot 0 \\
3 \cdot 5 \\
11 \cdot 3 \\
22 \cdot 4 \\
40 \cdot 0\end{array}$ & $\begin{array}{lr}0.7- & 1.8 \\
2.5- & 51.4 \\
5.0-99.7 \\
7.4-215.1\end{array}$ \\
\hline $\begin{array}{l}10-19 \\
20-29 \\
30-39 \\
40-49 \\
50-59 \\
\geqslant 60\end{array}$ & $\begin{array}{l}0.5 \\
1.0 \\
1.3 \\
1.6 \\
2 \cdot 4 \\
2 \cdot 3\end{array}$ & $\begin{array}{l}0 \cdot 1-2 \cdot 3 \\
0.8-2 \cdot 1 \\
0 \cdot 8-3 \cdot 0 \\
1 \cdot 1-4 \cdot 9 \\
0.8-6.6\end{array}$ & $\begin{array}{c}\text { After adjustme } \\
-1 \cdot 0 \\
0 \cdot 8 \\
3 \cdot 7 \\
6 \cdot 8 \\
14 \cdot 1\end{array}$ & $\begin{array}{lr}0 \cdot 1- & 4 \cdot 6 \\
0.6 & 21 \cdot 8 \\
1 \cdot 1- & 43.9 \\
1 \cdot 8-112.3\end{array}$ & $\begin{array}{r}- \\
1 \cdot 0 \\
3 \cdot 6 \\
6 \cdot 4 \\
9 \cdot 9 \\
12 \cdot 4\end{array}$ & $\begin{array}{l}0.6-22.4 \\
0.9-43.6 \\
1.3-74.0 \\
1.3-118.4\end{array}$ \\
\hline
\end{tabular}


Table 4 Relations of chronic bronchitis and lung dysfunction to smoking habits in 1363 male employees of the Kalgoorlie mineral industry, before and after adjustment for age and mining experience

\begin{tabular}{|c|c|c|c|c|c|c|}
\hline \multirow[b]{2}{*}{ Smoking habits } & \multicolumn{2}{|c|}{ Chronic bronchitis } & \multicolumn{2}{|c|}{$\begin{array}{l}\text { Chronic bronchitis with FEV } 1 / F V C \\
<70 \%\end{array}$} & \multicolumn{2}{|c|}{$\begin{array}{l}\text { Chronic bronchitis with } \\
\text { FVC }<80 \% \text { of predicted }\end{array}$} \\
\hline & $P O R$ & $95 \% C I$ & POR & $95 \% C I$ & POR & $95 \% C I$ \\
\hline $\begin{array}{l}\text { Non-smoker } \\
\text { Duration 0-9 years } \\
\text { Duration } 10-19 \text { years } \\
\text { Duration } \geqslant 20 \text { years } \\
20-29 \mathrm{cig} / \text { day }^{*} \\
\geqslant 40 \mathrm{cig} / \text { day }^{*} \\
\text { Current smoker } \dagger\end{array}$ & $\begin{array}{l}1 \cdot 0 \\
1 \cdot 1 \\
2 \cdot 2 \\
3 \cdot 4 \\
1 \cdot 2 \\
1 \cdot 3 \\
1 \cdot 8\end{array}$ & $\begin{array}{l}0 \cdot 5-2 \cdot 3 \\
1 \cdot 1-4 \cdot 4 \\
1 \cdot 7-6 \cdot 8 \\
0 \cdot 8-1 \cdot 8 \\
0 \cdot 7-2 \cdot 4 \\
1 \cdot 1-2 \cdot 7\end{array}$ & $\begin{array}{c}\text { ustmen } \\
1.0 \\
1.4 \\
1.5 \\
12.5 \\
1.5 \\
1.7 \\
2.6\end{array}$ & $\begin{array}{l}0.1-16.4 \\
0.1-16.5 \\
1.4-113.8 \\
0.7-\quad 3.0 \\
0.6-4.9 \\
1.0-6.7\end{array}$ & $\begin{array}{l}1.0 \\
1.0 \\
0.8 \\
6.8 \\
1.5 \\
1.6 \\
1.0\end{array}$ & $\begin{array}{l}0.2-5 \cdot 7 \\
0 \cdot 1-4 \cdot 8 \\
1.6-28 \cdot 7 \\
0.7-3 \cdot 2 \\
0.5-5 \cdot 0 \\
0.4-2 \cdot 4\end{array}$ \\
\hline $\begin{array}{l}\text { Non-smoker } \\
\text { Duration } 0-9 \text { years } \\
\text { Duration } 10-19 \text { years } \\
\text { Duration } \geqslant 20 \text { years } \\
20-39 \mathrm{cig} / \text { day } \\
\geqslant 40 \mathrm{cig} / \text { day } \\
\text { Current smoker } \dagger\end{array}$ & $\begin{array}{l}1 \cdot 0 \\
1 \cdot 1 \\
1 \cdot 7 \\
1 \cdot 4 \\
1 \cdot 3 \\
1 \cdot 3 \\
2 \cdot 4\end{array}$ & $\begin{array}{l}0.5-2.5 \\
0.8-3.5 \\
0.6-3.0 \\
0.9-1.9 \\
0.7-2.4 \\
1.5-3.9\end{array}$ & $\begin{array}{c}\text { estment } \\
1.0 \\
1.9 \\
1.4 \\
2.2 \\
1.8 \\
1.7 \\
4.4\end{array}$ & $\begin{array}{lr}0.1- & 25.8 \\
0.1- & 16.2 \\
0.2- & 22 \cdot 3 \\
0.9 & 3.9 \\
0.6- & 5 \cdot 1 \\
1.6- & 12.3\end{array}$ & $\begin{array}{l}1.0 \\
1.8 \\
0.6 \\
1.5 \\
1.5 \\
1.7 \\
1.7\end{array}$ & $\begin{array}{l}0.3-11.4 \\
0.1-3.8 \\
0.3-7.5 \\
0.7-3.4 \\
0.5-5.3 \\
0.7-4.1\end{array}$ \\
\hline
\end{tabular}

*Effective relative to $1-9$ cigarettes a day smokers.

†Effect relative to ex-smokers.

in this category. Empirically, exclusive surface mining had a small effect, but meaningful inference was made difficult by wide confidence intervals.

On the basis of results reported in table 5 , it may be estimated that according to duration of mining experience, between $46 \%$ and $80 \%$ of cases of chronic bronchitis in the underground gold miners in this study were attributable to the effects of their work. The average attributable proportion of chronic bronchitis in all underground miners was estimated to be $50 \%$. Aetiological fractions of chronic bronchitis complicated by obstructive lung disorder and due to mining were similar to those of chronic bronchitis, whereas higher proportions of chronic bronchitis with restrictive lung disorder were attributed to the effects of mining. The average attributable proportion of the latter combination of conditions in all underground miners was $\mathbf{7 8 \%}$. Although it was estimated that $22 \%$ of cases of chronic bronchitis in exclusive surface miners were related to mining, this fraction was imprecise due to a large potential for random error.

Table 5 Relations of chronic bronchitis and lung dysfunction to mining experience in 1363 male employees of the Kalgoorlie mineral industry, before and after adjustment for age and smoking habits

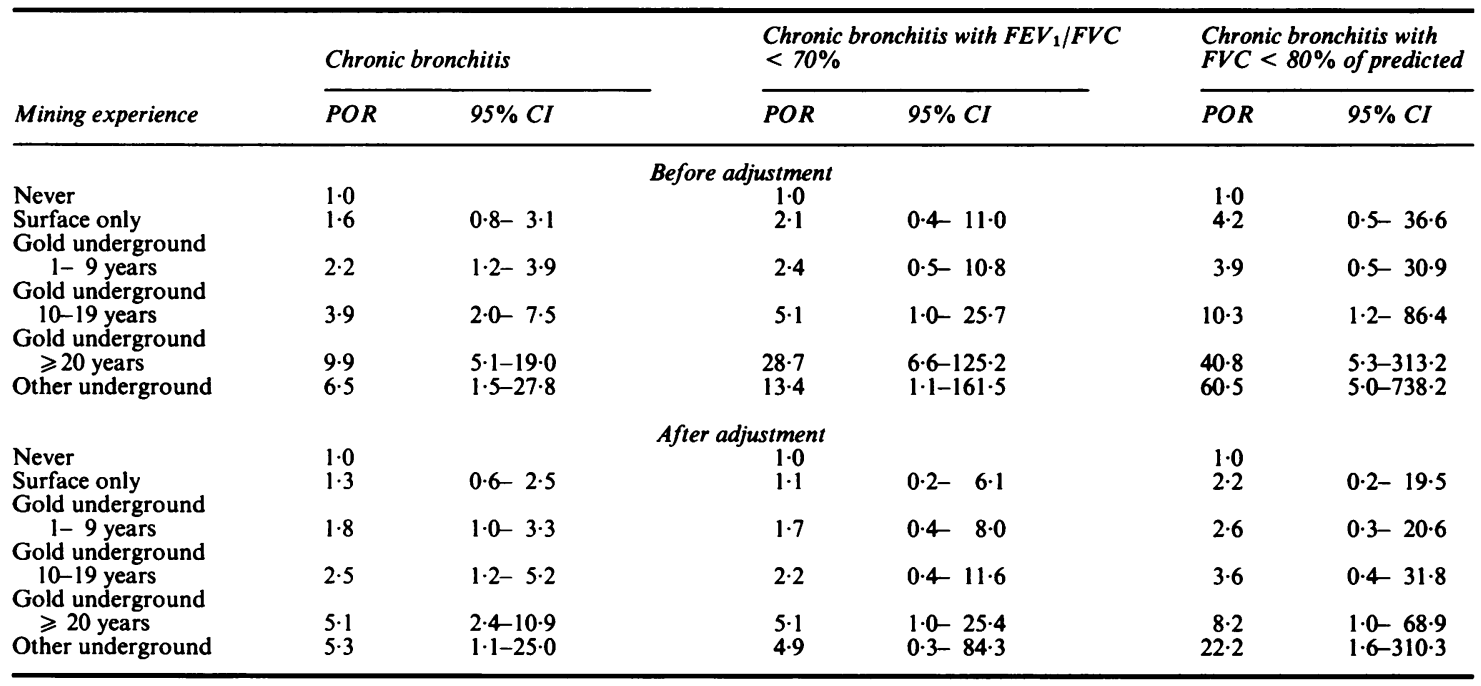


INTERACTION BETWEEN SMOKING AND UNDERGROUND MINING

To explore the possibility that smoking and underground mining act synergistically in causing chronic bronchitis and lung dysfunction, we examined the interaction between the two factors. The results, adjusted for age, are shown in table 6 . The presence of interaction empirically will often depend on how interaction is defined - that is, whether by use of an additive or multiplicative baseline. Positive interaction between smoking and underground mining, however, was observed in this study on both additive and multiplicative scales. Within current and exsmokers the POR of chronic bronchitis in underground miners $(5 \cdot 2)$ was 1.9 times higher than the POR in non-miners (2.7; see table 6$)$. This compared with a POR of 1.4 contrasting non-smoking underground miners with non-miners who had never smoked. Therefore, the index of synergy on a multiplicative scale was $S_{M}=5.2 /(1.4 \times 2.7)=1.4$ with a $95 \%$ confidence interval of $0 \cdot 3-7 \cdot 3$. On an additive scale the index of synergy was $S_{A}=(5 \cdot 2-1) /(1.4+$ $2 \cdot 7-2)=2 \cdot 0$ with a $95 \%$ confidence interval of 0.4-9.6.

Evidence of interaction between smoking and underground mining was also seen within the data set for chronic bronchitis combined with restrictive lung disorder, where $S_{M}=1.6$ and $S_{A}=2.5$ (see table 6) but the potential for random error in these results was greater than for chronic bronchitis. When a similar analysis was attempted for chronic bronchitis and obstructive lung disorder, it failed because of insufficient cases of disease in the non-smoking, nonmining reference group.

\section{Discussion}

The respiratory health of the Kalgoorlie mining worker has ample scope for improvement. Fourteen per cent of the male workforce suffered from chronic bronchitis and around 9-11\% had abnormal lung function tests. In contrast to these high proportions of symptomatic and functional disorders the preva- lence of radiographically diagnosed silicosis was low-only $1 \%$.

In 1961-2 the prevalence of chronic bronchitis was $10 \%$ in surface workers and $27 \%$ in underground workers, all having more than ten years experience in the gold mining industry. ${ }^{15}$ To compare the present results to those observed in 1961-2, it was necessary to apply the same ten year selection criterion and to adjust for differences in the age structures of the two survey populations (the mining workforce in 1961-2 had an older age structure than in 1985). When these adjustments were made, the comparable proportions of surface and underground miners with chronic bronchitis in 1985 were $13 \%$ and $29 \%$ respectively. Therefore, at best, there had been little change in the prevalence of chronic bronchitis, despite a reduction in the proportion of miners who were current smokers from $69 \%$ in $1961-2$ to $56 \%$ in 1985 . In $1961-2$ the prevalence of radiographically diagnosed silicosis was $22 \% .{ }^{15}$ Unlike chronic bronchitis it would appear that silicosis has come under effective control due to lower levels of respirable dust and exclusion of miners who show early evidence of silicosis on routine screening.

\section{CHRONIC BRONCHITIS AND MINING WORK}

Our results provide strong support for the existence of chronic bronchitis as an occupational health prob lem in the gold mining industry. The rate of chronic bronchitis with or without coincident lung function abnormalities increased with greater duration of exposure to underground mining. This observation is consistent with the associations of chronic bronchitis and obstructive lung disorder with underground work observed in gold mines in South Africa. ${ }^{13} 14$ Thus of three studies which have examined the effect of underground gold mining on the development of chronic bronchitis, all have yielded positive conclusions. The present results are also consistent with the view that other types of underground mining increase the rates of chronic bronchitis and respiratory dysfunction. ${ }^{11226}$

Table 6 Relations of chronic bronchitis and abnormal lung function to the interaction between underground mining and smoking in 1363 male employees of the Kalgoorlie mineral industry, adjusted for age

\begin{tabular}{|c|c|c|c|c|c|c|}
\hline \multirow{2}{*}{$\begin{array}{l}\text { Smoking/ } \\
\text { underground mining }\end{array}$} & \multicolumn{2}{|c|}{ Chronic bronchitis } & \multicolumn{2}{|c|}{$\begin{array}{l}\text { Chronic bronchitis with FEV } / F V C \\
<70 \%\end{array}$} & \multicolumn{2}{|c|}{$\begin{array}{l}\text { Chronic bronchitis with } \\
\text { FVC }<80 \% \text { of predicted }\end{array}$} \\
\hline & $P O R$ & $95 \% \mathrm{CI}$ & POR & $95 \% C I$ & $P O R$ & $95 \% C I$ \\
\hline $\begin{array}{l}\text { No/no } \\
\text { No/yes } \\
\text { Yes/no } \\
\text { Yes/yes }\end{array}$ & $\begin{array}{l}1 \cdot 0 \\
1.4 \\
2.7 \\
5 \cdot 2\end{array}$ & $\begin{array}{l}0 \cdot 5-4 \cdot 1 \\
1 \cdot 1-6 \cdot 6 \\
2 \cdot 1-12 \cdot 8\end{array}$ & $\begin{array}{l}1.0 \\
-* \\
-^{*} \\
{ }^{*}\end{array}$ & & $\begin{array}{l}1 \cdot 0 \\
1 \cdot 3 \\
1 \cdot 9 \\
4 \cdot 1\end{array}$ & $\begin{array}{l}0.1-17.9 \\
0 \cdot 2-17 \cdot 0 \\
0.4-38.2\end{array}$ \\
\hline
\end{tabular}

*Unable to estimate because of model instability. 
Three potential sources of systematic error in this study were selection bias operative in the recruitment and retention of mining workers; confounding of the effects of underground mining with age, smoking, and other extraneous factors; and information bias due to exposure or disease misclassification. Although the extent of selection bias would have been reduced by our use of exposure contrasts formed within the mineral industry, there was still potential for people with chronic bronchitis to be excluded from underground mining. It was also possible that an underground miner who developed chronic bronchitis was more likely to change his occupation than a surface miner or non-miner. The effect of such a bias would have been to reduce the apparent strength of the associations of chronic bronchitis and respiratory dysfunction with underground mining.

Confounding by age and smoking were controlled in the analysis by use of logistic regression. Because of the discrete categorisation of age and smoking variables, some residual confounding may have been present. It is unlikely, however, that this could account for the fivefold to eightfold gradients in relative risk that persisted after adjustment for age and smoking. Confounding by other factors such as hereditary, atmospheric pollution, or socioeconomic status was minimised by using a reference category within the same industry and same geographic location as the exposed groups.

Underground miners may possibly have differed from other workers in their predisposition to report symptoms of chronic bronchitis. If it occurred at all the likely direction of this information bias was towards underreporting of symptoms by underground miners. A few miners were suspicious that poor performance in the survey might result in failure to renew their mining certificates. Of greater concern was the possibility of non-differential misclassification of exposure level. Our aim was to measure the health effects of airborne contaminants in the gold mining industry, but as personal lifetime exposure levels were not available the duration of work in different mining environments was used as a surrogate measure. Because individual exposure levels to dust and other noxious agents (such as fumes from explosives and diesel) would have varied with type of occupation and the calendar period of underground employment (assuming that levels have varied over time) some misclassification resulting from the use of duration of underground mining must be expected. The bias resulting from this presumably random misclassification would have been towards the null condition of no observed effect.

It follows from the considerations outlined above that, on balance, the direction of systematic error in the present results was most likely towards conser- vatism rather than overestimation. Whereas we are confident of the existence of associations of chronic bronchitis and respiratory dysfunction with underground mining in Kalgoorlie, we are reluctant to draw any inference on the effect of exposures received during surface mining work. It is biologically plausible that surface dust exposure, for example, might have a small adverse effect but it was beyond the power of our study to measure such an effect with adequate precision.

\section{ATTRIBUTION OF CAUSE}

On the basis of this survey, the best estimate of the proportion of cases of chronic bronchitis in underground miners caused by occupational factors is $50 \%$. According to duration of employment in underground mining, the probability of an occupational cause in individual cases is estimated to vary from $40 \%$ to $80 \%$.

Unlike the study of miners in the Appalachian coal fields, ${ }^{12}$ we found no evidence that the adverse effect of underground work was confined to non-smokers. To the contrary, within the survey data there was positive interaction between smoking and underground mining such that the effect of underground work was greater in smokers than in non-smokers. The potential for random error in this result must be emphasised, but if the existence of synergism is confirmed by further research it would indicate that the proportion of cases of chronic bronchitis attributable to occupational factors is higher in smokers than in nonsmokers. This would occur if some cases of disease are caused by the combination of smoking and industrial exposures underground being preventable if either factor is removed.

This scientific report alone is not an adequate basis on which to formulate revised workers compensation policy for underground miners disabled by chronic bronchitis and respiratory dysfunction. It is hoped, however, that the evidence accumulating on this subject will stimulate a reappraisal of the existing situation. While the present study strengthens the case for compensation, there is one important caveat that must be attached to this support. The present study pertains to the occurrence of symptoms of chronic bronchitis and predominantly mild respiratory dysfunction in a working population. If, as has been postulated, ${ }^{1}$ occupational exposure induced respiratory changes are confined to larger airways and therefore relatively benign then the results presented here cannot be generalised with any certainty to miners disabled by severe and progressive respiratory impairment.

Regardless of whether chronic bronchitis caused by industrial exposures is a benign or progressive condition, all reasonable actions should be taken to reduce 
its occurrence. To this end the aims of dust suppression and ventilation in the gold mining industry may require reappraisal.

Members of the survey team were $J$ Anstead, G Bainbridge, $P$ Brewster, J Brown, S Brown, D Clarke-Hundley, D Coid, A Dunn, K Garrod, M Hatton, K Howell, C Juricev, H Lammle, R Lim, J Masters, A Meek, D Moore, D O'Neil, L Stirling, V Waddell, and R Willday. We thank the Chamber of Mines, Australian Worker's Union (Mining Division), and the mining industry, both employers and employees, for their considerable cooperation.

\section{References}

1 Morgan WKC. Industrial bronchitis. $\mathrm{Br} J$ Ind Med 1978;35:285-91.

2 Morgan WKC, Lapp NL, Seaton D. Respiratory disability in coal miners. JAMA 1980;243:2401-4.

3 Elmes PC. Relative importance of cigarette smoking in occupational lung disease. Br J Ind Med 1981;38:1-13.

4 Thackrah CT. The effects of arts, trades and professions and of civic states and habits of living on health and longevity. London: Longman, 1932.

5 Casey KR. Industrial bronchitis. In: Rom WN, ed. Environmental and occupational medicine. Boston: Little, Brown and Co, 1983:267-72.

6 Higgins ITT. Epidemiology of bronchitis and emphysema. In: Fishmen AP, ed. Pulmonary diseases and disorders. New York: McGraw-Hill, 1980:470-5.

7 Medical Research Council. Chronic bronchitis and occupation. Br Med J 1966;i:101-2.

8 Lowe JP, Campbell H. Evolution of disability in coalworkers' pneumonconiosis. Thorax 1976;31:527-33.

9 Gilson JC. Occupational bronchitis. Proc $R$ Soc Med 1970;63:857-64.

10 Lyons JP, Campbell H. Evolution of disability in coalworker's pneumonconiosis. Thorax 1976;31:527-33.

11 Irwig LM, Rocks P. Lung function and respiratory symptoms in silicotic and nonsilicotic gold miners. Am Rev Respir Dis 1978;117:429-35.

12 Kilbelstis JA, Morgan EJ, Reyer R, Lapp NL, Seaton A,
Morgan WKC. Prevalence of bronchitis and airway obstruction in American bituminous coal miners. Am Rev Respir Dis 1973;108:886-93.

13 Wiles FJ, Fovre MH. Chronic obstructive lung disease in gold miners. In: Walton WH, ed. Inhaled particles $I V$. Oxford: Pergamon, 1977:727-35.

14 Sluis-Cremer GK, Walters LG, Sichels HS. Chronic bronchitis in miners and non-miners: an epidemiologic survey of a community in the gold mining area in the Transvaal. Br J Ind Med 1967;24:1-12.

$15 \mathrm{McNulty}$ JC. The prevalence of respiratory symptoms in Western Australian gold miners compared with coal miners. In: Proceedings of the first Australian Pneumoconiosis Conference, February 12-14, 1968. Sydney: University of Sydney, 1968:411-27.

16 Medical Research Council. Questionnaire on respiratory symp toms. Instructions to interviewers. London: Medical Research Council, 1976.

17 American Thoracic Society. ATS statement-Snowbird workshops on standardisation of spirometry. Am Rev Respir Dis 1979;119:831-8.

18 National Health and Medical Research Council. Approved occupational health guide. Occupational respiratory disease and spirometry. Canberra: Commonwealth Department of Health, 1982.

19 Nie NH, Hull CH, Jenkins JG, Steinbrenner K, Bent DH. SPSS. Statistical package of the social sciences. New York: McGrawHill Inc, 1975.

20 Wilson EB. Probable inference. The law of succession and statistical inference. Journal of the Americal Statistical Association 1927;22:209-12.

21 Kleinbaum DG, Kupper LL, Morgenstern H. Epidemiologic research. Principles and quantitative methods. Belmont, California: Wadsworth Inc, 1982.

22 Thomas CD. Program "RISK". Montreal: McGill University, 1980.

23 Miettinen OS. Estimability and estimation in case-referent stude ies. Am J Epidemiol 1976;103:226-35.

24 Rothman KJ. Synergy and antagonism in cause-effece relationships. Am J Epidemiol 1974;99:385-8.

25 Shigeoka JW. Pulmonary function testing. In: Rom WH, ed. Environmental and occupational medicine. Boston: Little, Brown and Co, 1983:99-112.

26 Rogan JM, Attfield MD, Jacobsen M, Rae S, Walter DD, Walton WH. Role of dust in the working environment in development of chronic bronchitis in British coal miners. Br $J$ Ind Med 1973;30:217-26. 